\title{
CLIMA ORGANIZACIONAL Y SATISFACCIÓN LABORAL EN EL PERSONAL OPERATIVO FEDERAL DEL PROGRAMA CARAVANAS DE LA SALUD EN TABASCO, MEXICO
}

\author{
Ángel Carballo Chiñas*, Heberto Romeo Priego Álvarez**, María Isabel Ávalos García***
}

\begin{abstract}
Carballo-Chiñas A., Priego-Álvarez H.R., Ávalos-García M.I. Clima organizacional y satisfacción laboral en el personal operativo federal del programa Caravanas de la Salud en Tabasco. México. Hitos de Ciencias Económico Administrativas 2015;21 (59): 43-52

RESUMEN
\end{abstract}

Objetivo: Conocer la percepción del clima organizacional y la satisfacción laboral del personal operativo federal del programa Caravanas de la Salud en Tabasco, México.

Material y método: Se realizó un estudio observacional, prospectivo de corte transversal en el personal operativo federal de Caravanas de la Salud en Tabasco, mediante un censo de 97 trabajadores activos al momento del estudio. Para la recolección de la información se utilizaron dos instrumentos integrados en un solo cuestionario denominado "COSL2014» dividido en tres apartados: 1) perfil sociodemográfico, 2) clima organizacional, y 3) satisfacción laboral.

Resultados: El 76\% de los trabajadores manifestaron la existencia de un clima organizacional favorable, en relación a la Satisfacción Laboral el $42 \%$ evidenció estar parcial a regularmente satisfechos.

Conclusiones: La percepción del personal operativo sobre el clima organizacional es favorable; sin embargo, la mayor parte del personal operativo reflejo parcial y regular satisfacción laboral, lo que a futuro pudiera generar conflictos en el desarrollo del programa.
Carballo-Chiñas A., Priego-Álvarez H.R., Ávalos-García M.I. Clima organizacional y satisfacción laboral en el personal operativo federal del programa Caravanas de la Salud en Tabasco. México. Hitos de Ciencias Económico Administrativas 2015;21 (59): 43-52

\section{ABSTRACT}

Objective: To know the perception of organizational climate and job satisfaction of federal operating personnel of the program Caravanas de la Salud in Tabasco, Mexico.

Material and method: An observational, prospective cross-sectional study in the federal operating personnel of Caravanas de la Salud in Tabasco was conducted through a survey of 97 active workers at the time of the study. To collect the information two integrated instruments were used in one questionnaire «COSL2014» divided into three sections: I. Sociodemographic profile, II. Organizational climate and III. Job satisfaction.

Results: $76 \%$ of workers demonstrated the existence of a favorable organizational climate in relation to job satisfaction showed $42 \%$ to regularly be partially satisfied.

Conclusions: The perception of the operational staff on the organizational climate is favorable; however most of the operational staff reflect parcial and regular Job Satisfaction, which could generate conflicts in future program development.

Palabras clave: Clima organizacional. Satisfacción laboral. Caravanas de la Salud.

Key words: SMC. Organizational climate. Job satisfaction. Caravanas de la Salud.

DIRECCIÓN PARA RECIBIR CORRESPONDENCIA:Correo electrónico: dr_carballo@hotmail.com

\footnotetext{
* Maestro en Ciencias en Salud Pública con énfasis en Administración de Servicios de Salud. Supervisor Estatal de Unidades Médicas de la Secretaría de Salud del Gobierno del Estado de Tabasco.

** Doctor en Ciencias de la Salud. Profesor Investigador de la División Académica de Ciencias de la Salud (DACS). Universidad Júarez Autónoma de Tabasco (UJAT). Cuerpo Académico de Administración en Salud.

*** Doctora en Ciencias de la Salud. Coordinadora de Calidad en el Centro de Salud de Tierra Colorada. Secretaría de Salud. Profesor Investigador DACS - UJAT. Cuerpo Académico de Administración en Salud.
}

Fecha de recibido: 7 de enero de 2015. Fecha de aceptación: 23 de febrero de 2015. 
urante casi cuatro décadas, la Secretaría de Salud ha desarrollado diversas estrategias y programas para extender la cobertura de servicios esenciales de salud mediante equipos itinerantes; destacan entre tales experiencias, en orden cronológico, en 1976 el Programa de Extensión de Cobertura (PEC), 1978 el Programa Comunitario Rural (PCR), 1981 el Programa de Salud Rural (PSR), de 1991 a 1995 opera el Programa de Apoyo a los Servicios de Salud para Población Abierta (PASSPA), el Programa de Ampliación de Cobertura (PAC) en 1996, en 1997 inicio el Componente de Salud del Programa Progresa (hoy Prospera) y desde el año 2007 el Programa Caravanas de la Salud, con el propósito de atender a poblaciones dispersas de comunidades caracterizadas por su tamaño y pocos habitantes, que residen en zonas orográficas de difícil acceso y que por lo tanto no tienen capacidad de acceder a la red de servicios de salud debido a esta ubicación geográfica (DOF, 2013).

En el Estado Mexicano de Tabasco, el programa Caravanas de la Salud se implementó en el año 2007 iniciando con 8 Unidades Médicas Móviles (UMM); debido al impacto de dicho programa en la población tabasqueña, actualmente se cuenta con 29 UMM federales conformadas con una plantilla operativa de 97 recursos humanos integrada por 29 médicos, 29 enfermeras, 29 promotores y 10 odontólogos.

El Clima Organizacional (CO) es un elemento fundamental en las percepciones que el trabajador tiene de las estructuras y procesos que ocurre en un medio laboral (Goncalves, 1997). El comportamiento y el desempeño de un individuo en el trabajo no dependen solamente de sus características personales, sino también de la forma en que esta percibe su clima de trabajo y los componentes de la organización (Brunet, 1987). La satisfacción laboral, se refiere a los sentimientos hacia la organización que se manifiestan mediante el orgullo de pertenecer a ella, y la identificación con sus objetivos y metas (Gorden J., 2000).

Por lo anterior, y dado el crecimiento organizacional e importancia en la operatividad del programa Caravanas de la Salud, es necesario conocer la percepción del clima organizacional y la satisfacción laboral del personal operativo; para optimizar el desempeño y diseñar estrategias de mejora para alcanzar los objetivos del programa y brindar una atención de calidad a la población usuaria.

\section{MARCO TEORICO CONCEPTUAL Clima Organizacional}

La Organización Panamericana de la Salud (OPS), define el desarrollo organizacional como un conjunto de actividades para llevar a cabo un cambio planeado, que tiene como base los valores humanistas, esto con el fin de mejorar la eficacia de la organización y el bienestar de los empleados.

Chiavenato (2005) menciona que el clima es el medio interno de la organización, la atmósfera psicológica y característica que existe en cada organización; el cual puede ser definido como las cualidades o propiedades del ambiente laboral que son percibidas 0 experimentadas por los miembros de la organización y que además tienen influencia directa en los comportamientos de los empleados.

Goncalves (2000), considera que el clima organizacional se relaciona con las condiciones y características del ambiente laboral las cuales generan percepciones en los empleados que afectan su comportamiento.

Como menciona Cortes (2009), la OPS y la Organización Mundial de la Salud (OMS) diseñaron un instrumento denominado: Inventario de Clima Organizacional, el cual aporta una herramienta evaluativa, aplicable en Salud Pública para determinar a través de cuatro dimensiones básicas: liderazgo, motivación, reciprocidad y participación el clima de una organización.

Chiavenato (2000), define liderazgo como la influencia que ejerce un individuo en el comportamiento de otras personas en la búsqueda, eficiente y eficaz, de objetivos previamente determinados, por medio de la habilidad de orientar y convencer (más que prescribir e imponer) a otros para ejecutar, con entusiasmo, las actividades asignadas.

Bennis (2009) define la motivación como un conjunto de reacciones y actitudes naturales, propias de las personas, que se manifiestan cuando determinados estímulos del medio circundante se hacen presentes. Castillo (1992) sintetiza bien el concepto a través de la siguiente definición «motivo es toda causa interna de orden intelectual, consciente o subconsciente, que 
puede activar una acción voluntaria e inducir a un comportamiento concreto en una situación social dada».

Koontz y Weihrich (1998) señalan que la motivación implica un impulso hacia un resultado mientras que la satisfacción es el resultado ya experimentado.

Por su parte, Likert y Gibson (1986) plantean que el clima organizacional es el término utilizado para describir la estructura psicológica de las organizaciones. El clima es la sensación, personalidad o carácter del ambiente de la organización, es una cualidad relativamente duradera del medio ambiente interno de una organización que experimentan sus miembros, influye en su comportamiento y puede describirse en términos de los valores de una serie particular de características o atributos de la organización.

Álvarez (1995), define el clima organizacional como el ambiente de trabajo resultante de la expresión o manifestación de diversos factores de carácter interpersonal, físico y organizacional. El ambiente en el cual las personas realizan su trabajo influye de manera notoria en su satisfacción y comportamiento, y por lo tanto, en su creatividad y productividad.

Para García (2003), el clima organizacional representa las percepciones que el individuo tiene de la organización para la cual trabaja y la opinión que se ha formado de ella en términos de variables o factores como autonomía, estructura, recompensas, consideración, cordialidad, apoyo, apertura, entre otras.

\section{Satisfacción Laboral}

Para Gorden, J. (2000), satisfacción «son los sentimientos hacia la organización que se manifiestan mediante el orgullo de pertenecer a ella, la identificación con sus objetivos y sus productos y con la complacencia por la contraprestación y el tratamiento recibido. Esta variable contempla 7 componentes: Orgullo-Identidad, Reconocimiento, Remuneración, Integración, Calidad Laboral, Desarrollo y Ambiente Interno»; es decir, la satisfacción en el puesto de trabajo es la complacencia que se siente al pertenecer a una organización determinada y en la cual se logra alcanzar objetivos y metas propuestas.
Paravic y Larraguibel citan a autores como Locke (1976, 1984), quien plantea que «la satisfacción laboral es producto de la discrepancia entre lo que el trabajador quiere de su trabajo y lo que realmente obtiene, mediada por la importancia que para él tenga, lo que se traduce en que a menor discrepancia entre lo que quiere y lo que tiene, mayor será la satisfacción».

Muchinsky (2000), define la satisfacción laboral como «el grado de placer que el empleado obtiene de su trabajo». Bravo (2002), la conceptualiza como «una actitud o conjunto de actitudes desarrolladas por la persona hacia su situación de trabajo».

Mientras que Reitz (1977, citado por Arellano, 2005), menciona que si el empleado no logra satisfacción con el trabajo, habrá consecuencias negativas de su comportamiento, como ausentismo, rotación de personal, retardos y apatía, por mencionar. En cambio, si se mantiene satisfecho se verá reflejado en actitudes positivas y buena realización de sus funciones. Sin embargo su satisfacción está determinada por sus características personales y el trabajo mismo.

Según Robbins (1999), la satisfacción laboral es la actitud general del individuo hacia su trabajo; específicamente se refiere a las actitudes del empleado hacia su trabajo real en comparación con su trabajo ideal, y la relación con su vida en general. De esta manera en el trabajo ideal influyen factores del propio empleado como: sus necesidades, valores, rasgos personales y habilidades. En ocasiones estos factores se ven afectados por aspectos del empleo como: comparaciones con otros empleados, condiciones favorables de trabajo, empleos anteriores, grupos de referencia, identidad y significación de la tarea; y característica del puesto: satisfacción con el salario, condiciones de trabajo, supervisión, autonomía, compañeros, contenido del puesto, recompensas, seguridad en el empleo y promociones.

Por otro lado, Salinas (1994), indica que la satisfacción laboral guarda una estrecha relación con determinados aspectos del desempeño, y se reconoce una vinculación causa-efecto positiva entre el clima organizacional y las actitudes favorables y desfavorables del trabajador.

Según Navarro (2008) la división más simple de la satisfacción laboral es la que distingue entre satisfacción 
laboral intrínseca y extrínseca. La intrínseca está originada por factores relacionados con la tarea en sí (variedad, dificultad, interés, autonomía, posibilidad de aprender, etc). Por su parte, la extrínseca tiene su origen en fuentes externas al empleado, ligadas al contexto o ambiente en el que la tarea se desarrolla (relaciones con los supervisores y con los compañeros, salario, horas de trabajo, seguridad, reconocimiento.

En el polo opuesto se sitúa la insatisfacción laboral como una respuesta emocional negativa hacia el puesto en tanto que este ignora, frustra o niega los valores laborales (Locke, 1976). De acuerdo por lo descrito por Ortiz (2008) la frustración que siente un empleado insatisfecho puede conducirle a una conducta agresiva, la cual puede manifestarse por sabotaje, maledicencia o agresión directa.

Al igual que ocurre con el clima organizacional, en la satisfacción laboral se identifican diversas dimensiones entre las que se encuentran los compañeros, la supervisión, el salario, las posibilidades de promoción y las tareas a realizar ver (Locke,1986).

Aún, cuando muchos autores no realizan una vinculación concluyente entre el clima laboral y satisfacción en el trabajo, Fernández y Sánchez (1996) destacan la vinculación del clima organizacional y la satisfacción laboral; en tanto, esta última «arranca en gran medida de la valoración que la persona realiza del conjunto de características que describen los estímulos que configuran su contexto de trabajo, la primera se refiere a la descripción del conjunto de características que percibe el individuo de su organización».

\section{METODOLOGÍA}

Se realizó un estudio observacional, prospectivo de corte transversal que se realizó con el Personal Operativo Federal adscrito al Programa Caravanas de la Salud en el Estado de Tabasco, México.

El universo estuvo conformado por 97 trabajadores activos en el Programa Caravanas de la Salud al momento de la investigación.

Para la percepción del Clima Organizacional se utilizó el instrumento Escala de Clima Organizacional (EDCO) (Acero, 2003). Para cada variable se asignaron cinco ítems con actitud positiva y cinco ítems de actitud negativa, (Padua, 1994) (Nunnaly,1970). El instrumento está conformado por 8 dimensiones y 40 reactivos, en una escala tipo Likert de 5 categorías, asignándose: 1 . Siempre; 2. Casi siempre; 3 . Algunas veces; 4. Muy pocas veces y 5 . Nunca, validado con un Alfa de Cronbach de 0.874 para la confiabilidad y consistencia del instrumento.

Para determinar si el Clima Organizacional puntúa entre alto, medio o bajo, se estimó la siguiente calificación: entre el puntaje mínimo y el máximo posible (40 y 200), correspondiendo para Nivel Bajo: De 40 a 93 puntos; Promedio: De 94 a 147 puntos y Nivel alto: Puntajes entre 148 y 200 . Un puntaje alto indica una alta frecuencia, relacionado con un buen Clima Organizacional y un puntaje bajo indica una baja frecuencia, relacionado con problemas dentro de la organización. Por consiguiente, el nivel alto es un Clima Organizacional favorable para las actividades laborales, por el contrario el nivel bajo es un Clima Organizacional poco propicio y en ocasiones conflictivo en el desarrollo del trabajo.

La Satisfacción Laboral fue identificada a través del instrumento denominado Escala de Satisfacción Laboral (SL-ARG) (Sívori R., Zavaleta F., 2013), conformado por 7 dimensiones y 43 reactivos, con respuestas múltiples en una escala tipo Likert, a través de 5 categorías, asignándole: 5 . Totalmente de acuerdo; 4 . De acuerdo; 3. Indiferente, 2. En desacuerdo y 1. Totalmente en desacuerdo, donde se obtuvo mediante el análisis de consistencia interna, validado con un Alfa de Cronbach de 0.928 para la confiabilidad y consistencia del instrumento.

Para la recolección de la información ambos instrumentos se integraron en un solo cuestionario denominado "Clima Organizacional y satisfacción laboral del personal Operativo de Caravanas de la Salud" (COSL2014), el cual consta de 3 apartados: 1) Perfil sociodemográfico, 2) Clima organizacional y 3) Satisfacción laboral.

Los datos fueron capturados en el paquete estadístico Stadistical Package for the Social Sciences (SPSS) versión 20. El tratamiento de los datos realizado fue estadística descriptiva, tablas de contingencia. 


\section{RESULTADOS}

Perfil sociodemográfico del personal operativo

Con la información recabada del censo del personal operativo federal adscrito al Programa Caravanas de la
Salud, se determinó que la mayor parte de la plantilla laboral (90\%) está conformada por médicos, enfermeras y promotores y la minoría (10\%) lo conformaron los odontólogos (ver tabla 1).

Tabla 1: Perfil sociodemográfico de los profesionales de la salud.

\begin{tabular}{|c|c|c|c|c|c|c|c|c|c|c|}
\hline \multirow{3}{*}{$\begin{array}{l}\text { Característica } \\
\text { s }\end{array}$} & \multicolumn{10}{|c|}{ PROFESIONALES DE LA SALUD } \\
\hline & \multicolumn{2}{|c|}{ Médico } & \multicolumn{2}{|c|}{ Enfermera } & \multicolumn{2}{|c|}{$\begin{array}{l}\text { Odontólog } \\
0\end{array}$} & \multicolumn{2}{|c|}{ Promotor } & \multicolumn{2}{|c|}{ Todos } \\
\hline & $\begin{array}{l}N= \\
29\end{array}$ & $30 \%$ & $\begin{array}{l}\mathrm{N}= \\
29\end{array}$ & $30 \%$ & $\begin{array}{l}N= \\
10\end{array}$ & $10 \%$ & $\begin{array}{l}N= \\
29\end{array}$ & $30 \%$ & $\begin{array}{l}N= \\
97\end{array}$ & $100 \%$ \\
\hline \multicolumn{11}{|l|}{ Edad: } \\
\hline $23-29$ años & 22 & 76 & 11 & 38 & 2 & 20 & 5 & 17 & 40 & 41 \\
\hline $30-36$ años & 7 & 24 & 14 & 48 & 4 & 40 & 10 & 34 & 35 & 36 \\
\hline $37-43$ años & - & - & 3 & 10 & 2 & 20 & 10 & 34 & 15 & 16 \\
\hline $44-52$ años & - & - & 1 & 3 & 2 & 20 & 4 & 14 & 7 & 7 \\
\hline \multicolumn{11}{|l|}{ Sexo: } \\
\hline Masculino & 8 & 28 & 4 & 14 & 7 & 70 & 29 & 100 & 48 & 49 \\
\hline Femenino & 21 & 72 & 25 & 86 & 3 & 30 & - & - & 49 & 51 \\
\hline \multicolumn{11}{|l|}{ Estado Civil: } \\
\hline Soltero (a) & 21 & 72 & 12 & 41 & 2 & 20 & 1 & 3 & 36 & 37 \\
\hline Casado (a) & 5 & 17 & 7 & 24 & 7 & 70 & 18 & 62 & 37 & 38 \\
\hline Viudo (a) & - & - & 1 & 3 & - & - & 1 & 3 & 2 & 2 \\
\hline Divorciado (a) & - & - & - & - & - & - & - & - & - & - \\
\hline U. Libre & 3 & 10 & 8 & 28 & 1 & 10 & 8 & 28 & 20 & 21 \\
\hline Separado (a) & - & - & 1 & 3 & - & - & 1 & 3 & 2 & 2 \\
\hline \multicolumn{11}{|l|}{ No. de hijos: } \\
\hline No tiene hijo & 24 & 83 & 13 & 45 & 5 & 50 & 1 & 3 & 43 & 44 \\
\hline 1 hijo & 5 & 17 & 9 & 31 & 1 & 10 & 11 & 38 & 26 & 27 \\
\hline 2 hijos & - & - & 5 & 17 & 3 & 30 & 13 & 45 & 21 & 22 \\
\hline 3 hijos & - & - & 2 & 7 & 1 & 10 & 4 & 14 & 7 & 7 \\
\hline 4 hijos o mas & - & - & - & - & - & - & - & - & - & - \\
\hline \multicolumn{11}{|l|}{$\begin{array}{l}\text { Nivel de } \\
\text { estudio: }\end{array}$} \\
\hline Secundaria & - & - & - & - & - & - & - & - & - & - \\
\hline Bachillerato & - & - & - & - & - & - & 16 & 55 & 16 & 17 \\
\hline Licenciatura & 27 & 93 & 29 & 100 & 9 & 90 & 13 & 45 & 78 & 80 \\
\hline Posgrado & 2 & 7 & - & - & 1 & 10 & - & - & 3 & 3 \\
\hline \multicolumn{11}{|l|}{$\begin{array}{l}\text { Antigüedad } \\
\text { laboral: }\end{array}$} \\
\hline $\begin{array}{l}\text { Inicial (0-2 } \\
\text { años) }\end{array}$ & 27 & 93 & 11 & 38 & 1 & 10 & 7 & 24 & 46 & 47 \\
\hline $\begin{array}{l}\text { Medio (3-5 } \\
\text { años) }\end{array}$ & 2 & 7 & 10 & 34 & 5 & 50 & 14 & 48 & 31 & 32 \\
\hline $\begin{array}{l}\text { Mayor (6 años } \\
\text { y mas) }\end{array}$ & - & - & 8 & 28 & 4 & 40 & 8 & 28 & 20 & 21 \\
\hline
\end{tabular}

Fuente: Censo de clima organizacional y satisfacción laboral en el personal operativo de Caravanas de la Salud (COSL2014). 
La edad se distribuyó en rangos entre 23 y 52 años, agrupándose en intervalos de 7; en el área médica el grupo de edad prevalente oscila entre $23-29$ años (76\%) lo que destaca que la mayor parte de los médicos son personal joven, en el área de enfermería la edad promedio encontrado fue entre los $30-36$ años (48\%) similar a lo observado en el personal de odontología (40\%), el último grupo de estudio conformado por los promotores de salud mostró un promedio de edad de 30-43 años (34\%).

El sexo predominante en el censo fue el femenino con un $51 \%$, mientras que el masculino representó el $49 \%$ del personal actualmente contratado. Para fines estadísticos se desglosó el sexo por cada área de salud, obteniendo que el $72 \%$ de los médicos son mujeres, del área de enfermería el 86\% corresponden al sexo femenino; situación contraria ocurre con el personal de odontología y promoción donde el sexo dominante es el masculino, con un $70 \%$ y $100 \%$, respectivamente, en este ultimo la contratación tiene una tendencia hacia el sexo masculino debido al tipo de actividad operativa y administrativa que desempeñan (operación de vehículos pesados y manejo de equipamiento).

De acuerdo a su estado civil se encontró que de los médicos el $72 \%$ refirió ser soltero, con relación a las enfermeras el $41 \%$ dijo ser soltera, mientras que en los odontólogos el $70 \%$ menciono estar casado y de igual manera los promotores en un $62 \%$. de poseer estudios de licenciatura (100\%), en el área odontológica se encontró que el $90 \%$ cuenta con licenciatura y el $10 \%$ restante con posgrado, por último en el área de promoción en su mayoría refirieron poseer estudios de bachillerato (85\%).

Para obtener la antigüedad laboral se agruparon los datos en tres grupos de análisis: Inicial (0-2 años), Medio (3-5 años) y Mayor (6 años y más), encontrando así que los médicos en su mayoría (93\%) se ubicaron en nivel Inicial, situación similar se observó en el personal de enfermería (38\%), en contraste el personal de odontología y promoción se ubicaron en nivel Medio (50\% y $48 \%$ respectivamente), lo anterior es debido al tipo de contratación que se maneja para el personal operativo de Caravanas de la Salud .

\section{Análisis del Clima Organizacional}

Para la estimación del nivel del clima organizacional, se conformaron los datos obtenidos en los siguientes criterios: bajo, promedio y alto. A través de este análisis, se obtuvo que el $76 \%$ de los encuestados manifestó la existencia de un clima favorable (nivel alto) en la organización; Ilama la atención que nadie lo considero como inadecuado o poco propicio (nivel bajo) (ver figura 1).

\section{Análisis de la satisfacción laboral}

Respecto a la satisfacción laboral, esta se midió en 5 escalas: Alta insatisfacción, parcial insatisfacción, regular, parcial satisfacción y alta satisfacción, teniendo
En cuanto al número de hijos, se obtuvo que la mayoría del personal dada su edad y estado civil, no tiene hijos, caso observado en los médicos (83\%), con menos porcentaje se encontró al personal de enfermería (45\%) y odontología (50\%), no así los promotores quienes dijeron tener 2 hijos (45\%).

Con respecto al nivel académico, para su análisis individual se desglosó por áreas, en el área médica el 93\% del personal refirió estudios de licenciatura y una minoría (7\%) tener haber concluido estudios de posgrado, en el área de enfermería de acuerdo al tipo de contratación todas cumplen con el criterio
Figura 1. Análisis del Clima Organizacional

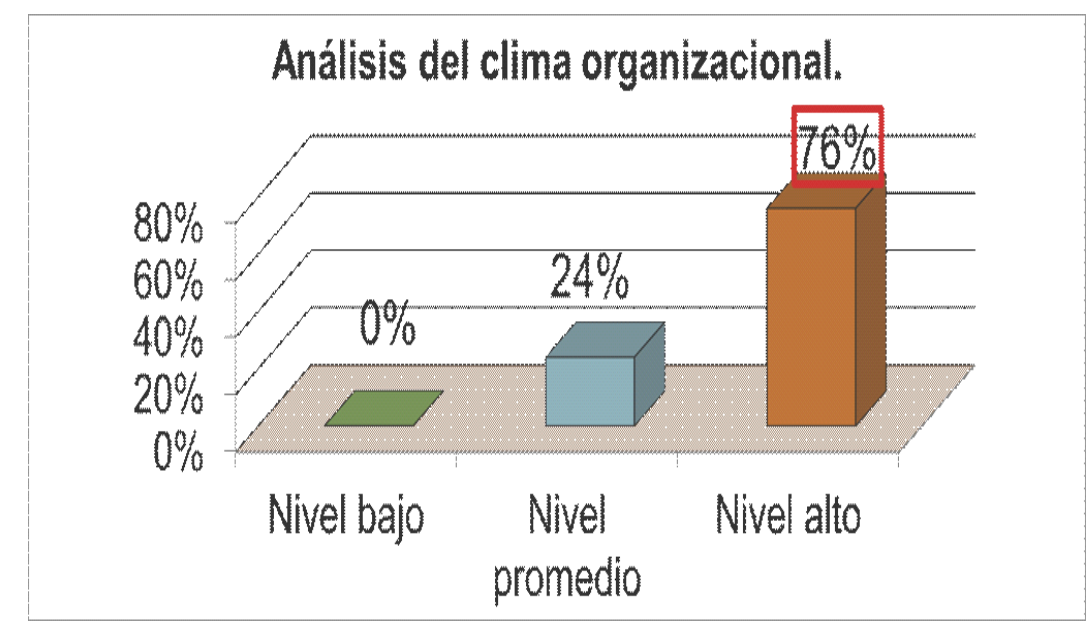

Fuente: COSL2014 
así que el $42 \%$ del personal mencionó tener una satisfacción laboral regular, en un $11 \%$ se observó una alta satisfacción, y una minoría $(3 \%)$ refirió alta insatisfacción laboral (ver figura 2).

\section{Análisis de las dimensiones del Clima Organizacional}

Se realizó un análisis de datos para valorar el clima organizacional y la satisfacción laboral; respecto a las dimensiones de estudio del clima organizacional, se encontró que la mayor parte del personal operativo presentó buena relación con su equipo de trabajo (93\%, relación interpersonal), un notorio porcentaje consideró

Figura 2. Análisis de la satisfacción laboral

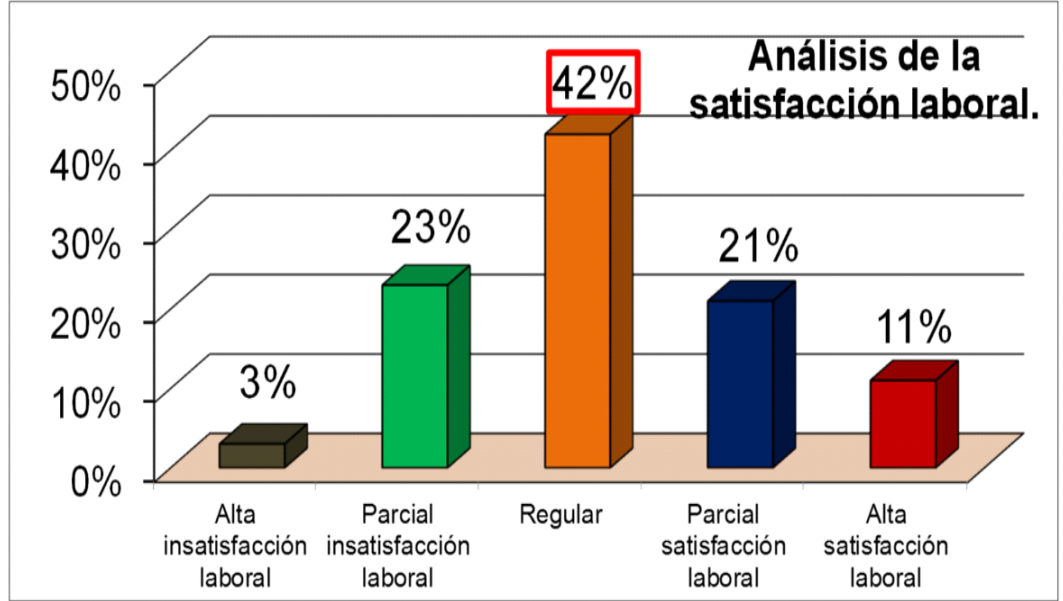

Fuente: COSL2014 que la Coordinación Estatal de Caravanas (Coordinador y Supervisores) apoya y estimula al personal (82\% estilo de dirección); se observó un alto sentido de pertenencia (un $76 \%$ dijo sentirse orgulloso de pertenecer al programa), el $99 \%$ de los encuestados mencionó estar conformes con la retribución percibida. Llama la atención que un número considerable refirió miedo al despido (66\% estabilidad) sobre todo por el tipo de contratación existente, lo que destaca en la misma proporción ( $66 \%$ claridad y coherencia) un desconocimiento prevalente sobre el futuro del programa; a pesar de eso se encontró alto estado de responsabilidad y cooperación en el personal (77\% valores), sin embargo, durante el análisis se encontró que un porcentaje notable de los encuestados (45\%) consideraron que no hay una correcta disponibilidad de los recursos para mejora de procesos, no se cuenta con equipos requeridos ni con el ambiente físico adecuado para el buen funcionamiento del programa (ver figura 3 ).

Análisis de las dimensiones de la satisfacción laboral

En cuanto a la satisfacción laboral que presentó el personal operativo, se observa una alta insatisfacción en lo referente a infraestructura y equipamiento (34\%), un alto porcentaje $(44 \%)$ se mostró parcialmente insatisfecho por la carencias de incentivos económicos y beneficios laborales, el personal operativo indicó

Figura 3. Análisis de la satisfacción laboral

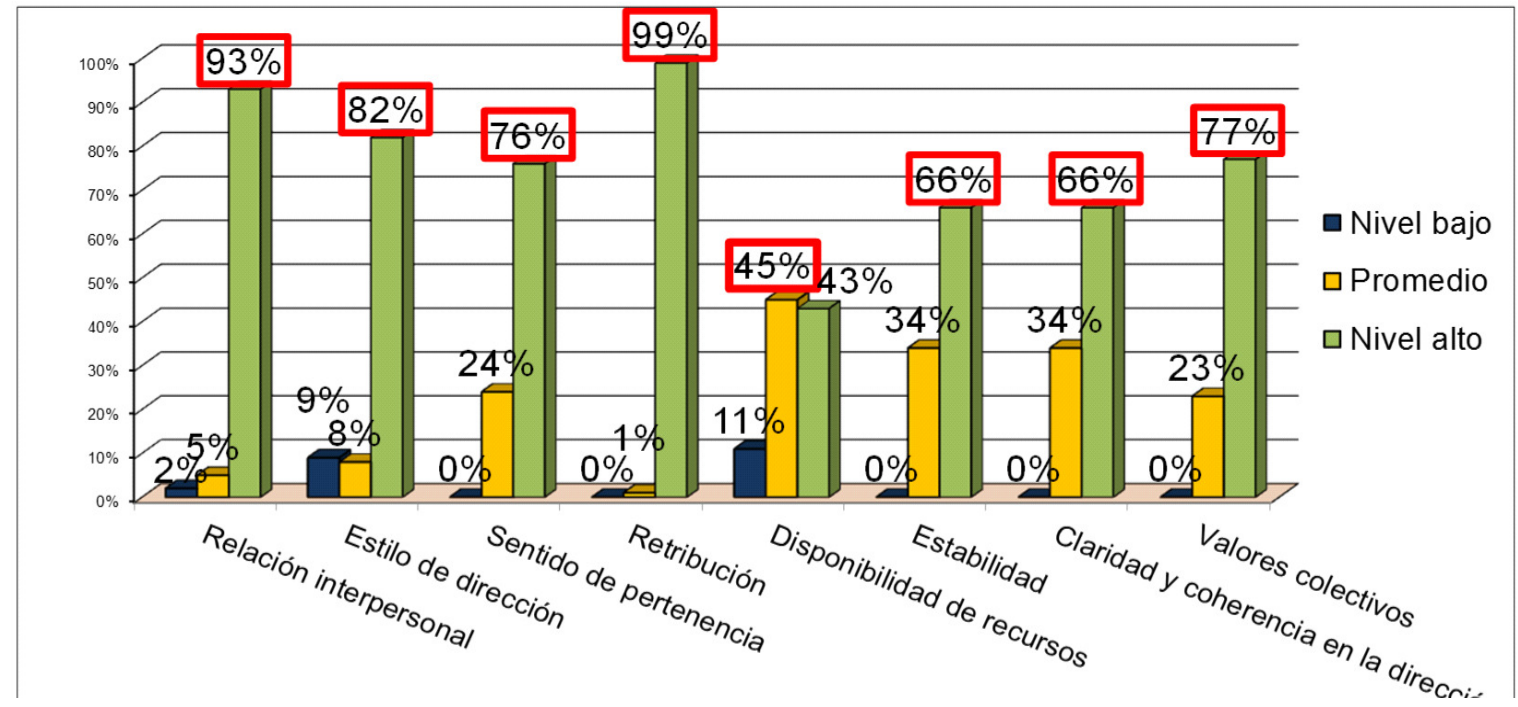

Fuente: COSL2014 
estar parcialmente insatisfechos (46\%) en relación a la supervisión, se evidenció una regular satisfacción en las relaciones interpersonales, vínculos de amistad y compañerismos (41\%), se observó una regular satisfacción (43\%) en las posibilidades de ascender y recibir capacitación para desempeñar su trabajo eficientemente, se encontró una notaria falta de comunicación Personal-Coordinación, ya que solo el $43 \%$ de los encuestados presentó una regular satisfacción en la trasmisión de la información entre los trabajadores y la Coordinación sobre aspectos relacionados al trabajo; y por último en relación al puesto de trabajo $(70 \%)$ mostraron una parcial insatisfacción laboral respecto a lo que realizan diariamente (ver figura 4).

\section{CONCLUSIONES}

Las dimensiones del clima organizacional con mayor puntuación en el estudio fueron: retribución, relaciones interpersonales, estilo de dirección, valores colectivos y sentido de pertenencia generando un mlima organizacional favorable. En general, se confirmó la existencia de un buen ambiente de trabajo establecido básicamente en la confianza en el personal y buen trato por parte del personal gerencial, logrando relaciones interpersonales óptimas, que se espera mejoren la rentabilidad del programa.

En contraparte, se percibió una parcial insatisfacción laboral, relacionadas primordialmente por las condiciones de trabajo, infraestructura y equipamiento que impiden al personal desarrollar sus destrezas y conocimientos por insuficiencia en los insumos para la ejecución y optimización de los procesos.

Figura 4

Análisis de las dimensiones de la satisfacción laboral

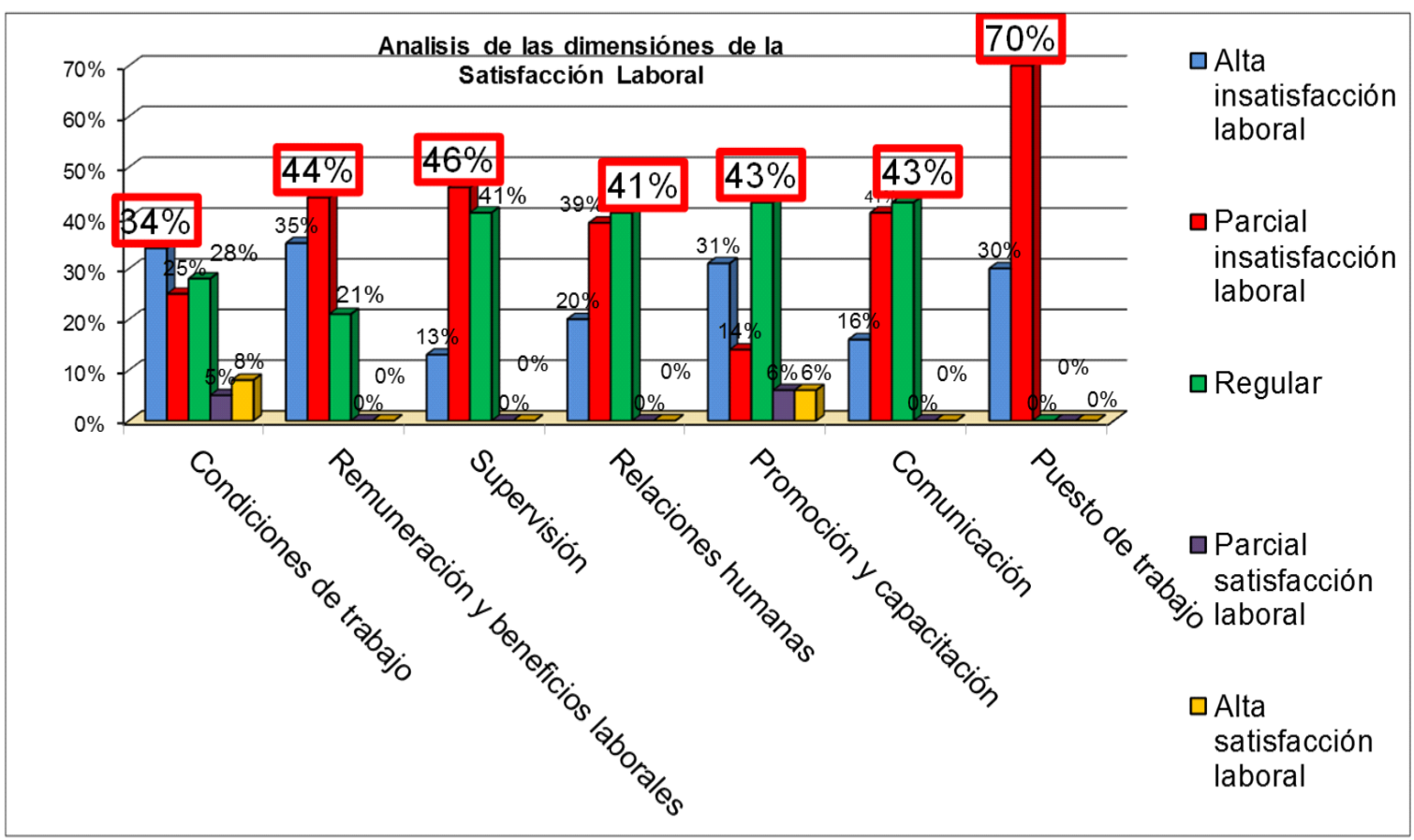

Fuente: COSL2014 


\section{REFERENCIAS}

Acero, Y. (2007). Escala de clima organizacional. Colombia: Fundación Universitaria Konrad Lorenz.

Álvarez, H. (1995). Modelo Hacia un Clima Organizacional Plenamente Gratificante. Universidad del Valle. Colombia

Araque M. (2009) Clima organizacional en el área de hospitalización de la clínica popular «Dr. Pedro Felipe Arreaza Calatrava», Catia, Caracas. Tesis de Licenciatura. Universidad Central de Venezuela. Recuperado de: http://saber.ucv.ve

Arellano G., D. (2005). Gestión Estratégica para el Sector Publico: Del Pensamiento Estratégico al Cambio Organizacional. México. Fondo de Cultura Económica

Bravo, M. (2002). Satisfacción laboral: Tratado de Psicología del Trabajo. La actividad laboral en su contexto. España. I: 343-394

Brunet L. (2004). El clima de trabajo en las organizaciones: definición diagnostica y consecuencias. México: Trillas. Recuperado de: http://www.eumed.net/libros-gratis

Castillo, A.M. (1992). Teoría y práctica de la motivación. $2^{2}$ Edición. Málaga: Facultad de Ciencias Económicas y Empresariales. Universidad de Málaga.

Chiavenato, I. (2000). Administración de los Recursos Humanos. Colombia: Mc Graw Hill. Recuperado de: http://www.eumed.net/libros-gratis

Chiavenato I. (2005). Comportamiento Organizacional. La Dinámica del éxito en las organizaciones. Segunda Edición. México: Mc Graw Hill.

Cortés N., Riande G. (2009). Diagnóstico del clima organizacional. Hospital Dr. Luis F. Nachón, Xalapa, Ver. Tesis de Maestría. Universidad Veracruzana (UV). México. Recuperado de: http://cdigital.uv.mx/ handle/123456789/30006

Fernández M. y Sánchez J. (1996). Manual de prácticas de psicología organizacional. España: Ediciones Amarú.
García, M. (2003). Del Clima organizacional a la cultura organizacional. En: II Encuentro de Investigación y docencia en administración. Asociación Colombiana de facultades de Administración - ASCOLFA. Cali: Universidad del Valle.

Goncalves A. (1997) Clima organizacional. Recuperado de: http://www.phpartners.com/ articulos/download.asp

Gorden J. (2000). Comportamiento organizacional. 5 Edición. México. Prentice Hall.

Goncalves, A. (2000). Fundamentos del clima organizacional. Sociedad Latinoamericana para la calidad (SLC).

Koontz, H. (1998). Administración: una perspectiva global. México: McGraw-Hill.

Likert, R. y Gibson, J. (1986) Nuevas Formas para Solucionar Conflictos. Editorial Trillas.

Muchinsky P. (2000). Psicología aplicada al trabajo. 1ra Edición. España: Ediciones Paraninfo.

Navarro, E. (2008). Revisión de la motivación de los trabajadores de la construcción: 1968-2008, Revista de la Construcción. Chile, 7 (2): 17-27.

Paravic, T. (2000) Satisfacción laboral de mujeres académicas de una universidad en Chile. Ciencia y Enfermería. Revista Interamericana de Investigación. Colombia. (6):1-5.

Reglas de Operación del Programa Caravanas de la Salud (2014), México: Diario Oficial de la Federación.

Robbins, S. (1999). Fundamentos del comportamiento organizacional. México: Prentice Hall.

Salinas, C. (1994) La satisfacción laboral y su papel en la evaluación de la calidad de la atención médica. Instituto Nacional de Salud Pública. México. 36(1): 22-29 